\title{
OPTIMUM RELIABILITY OF A STEEL TAPERED PORTAL FRAME STRUCTURE EXPOSED TO FIRE
}

\author{
Tamás Balogh, László Gergely Vigh \\ Budapest University of Technology and Economics, Department of Structural Engineering. \\ 3-9. M egyetem rkp., Kmf. 85, Budapest, H-1111, Hungary
}

\begin{abstract}
In this study, the optimum reliability of a tapered steel portal frame structure is presented for several cases. The aim of the research is to define target reliability indices for fire design situation since some research works (Balogh and Vigh, 2015a; 2015b) pointed that the achievable reliability (with using the prescriptive rules of Eurocode standards) is lower in extreme and seismic design situations than the suggested target value in (EN0, 2002). It seems that the target reliability indices of (JCSS, 2000) are preferable in these cases. In this paper, the optimum reliability is investigated as described in (Holickỳ, 2011), but total cost function is formulated with two decisive variables with respect to the amount of active and passive safety measures. The structural reliability is obtained with the help of a complex FORM (First Order Reliability Method) algorithm. The results of this investigation can help also to answer the question, whether active or passive safety measures are more effective tools to achieve optimal solutions in case of fire design of steel portal frames.
\end{abstract}

Keywords: Structural Reliability, Tapered Portal Frame, Active and Passive Safety Measures

\section{INTRODUCTION}

The appropriate reliability level of a structures exposed to fire can be ensured on different ways, using active and/or passive fire safety measures. First of all, as the most obvious case, the structure can be strengthened in order to avoid the failure on high temperature when the strength and stiffness of the material is considered on a reduced value. Passive protection measures, such as intumescent coating, can reduce the temperature of the protected elements. The active protection tools (e.g. alarm and water extinguish system) result safer solutions by decreasing the possibility of ignition and flashover.

Holickỳ in (Holickỳ, 2011) showed a method for calculation of the optimum reliability for a general example with a few random variables. In (Holickỳ et al., 2001) a Bayes belief network related to fire design, a simple example and the effectiveness of different safety measures was presented. The active safety measures can be used together with passive protection as well. However, due to the complexity and high nonlinearity of the fire design problem, the cheapest/optimal solution can be hardly found with trial-and-error process. In this paper the authors present an investigation defining the optimum reliability of a tapered steel frame structure in which the cost function is formulated with two decisive variables.

\section{INVESTIGATED STRUCTURE}

The analysed structure within this paper is a tapered portal frame structure which is used as a warehouse (Fig. 1a). S355 structural steel material is selected for the primary elements of the frames. Approximately at the middle of the eave height the columns are rotationally restrained against torsion and altogether six additional brace elements (equally distributed in the roof level) prevent the lateral torsional bucking failure of beams. For the fire design situation, the requirements and recommendations of (EN1-2, 2002) and (EN3-2, 2005) are considered. Rubber tires are stored in the facility, which makes the fire design problem very demanding with its design fire load $q_{f, d}=1500 \mathrm{MJ} / \mathrm{m}^{2}$ on the area of $450 \mathrm{~m}^{2}$. The gas temperatures have been obtained with Ozone software (Cadorin et al., 2001). Further details can be found in (Balogh and Vigh, 2015a). 
The investigated frame is protected with intumescent coating. The appropriate thickness of this passive safety measure is based on the section factor and the critical temperature of the element. The basis of the design of intumescent coating is the ISO standard fire curve indirectly since the thicknesses in design sheets have been obtained by testing according to (EN 13381-8, 2013) where ISO curve is prescribed for furnace testing. The intumescent paint of a Hungarian producer (Dunamenti, 2015) is considered in this study, the thicknesses (Fig. 1b) have been calculated for 30 minutes fire resistance.

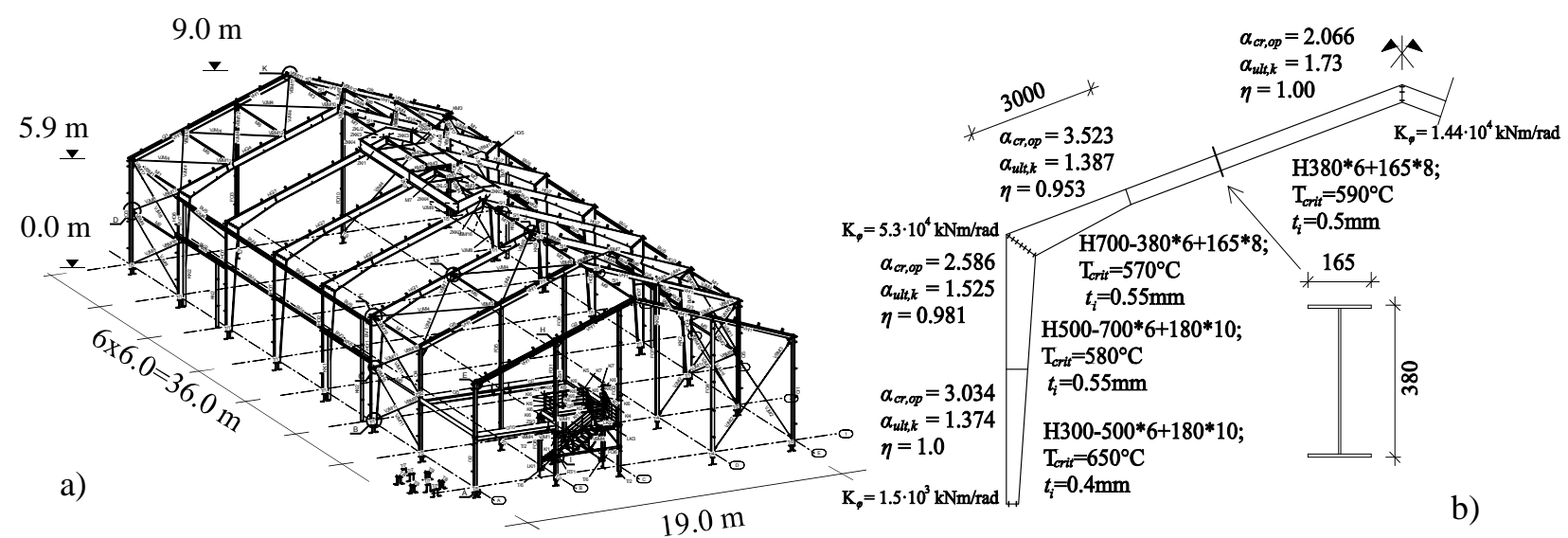

Fig. 1 a) Investigated structure; b) Calculation details related to prescriptive fire design

\section{THE PROBABILITY OF STRUCTURAL FAILURE}

The probability of failure under fire exposure contains the probability of occurrence of two independent events, namely the probability of severe fire and the conditional probability of failure if the severe fire is occurred. Accordingly, the problem can be formulated as follows:

$$
P_{\text {failurensevere fire }}=P_{\text {failure severe fire }} \cdot P_{\text {fire }} \leq P_{t}=\Phi\left(-\beta_{t}\right) \text {. }
$$

The calculated failure probability should be lower than a certain target value $\left(P_{t}\right)$ as it is given in (EN0, 2002) and (JCSS, 2000) standards. $\Phi(-)$ refers to cumulative distribution function of standard normal distribution function and $\beta$ is the so-called reliability index.

The passive and active safety measures can be easily separated in the calculation since the first probability is dependent on the active safety measures (Fig. 2), while the second probability depends on the amount of applied passive protection (Fig. 3).

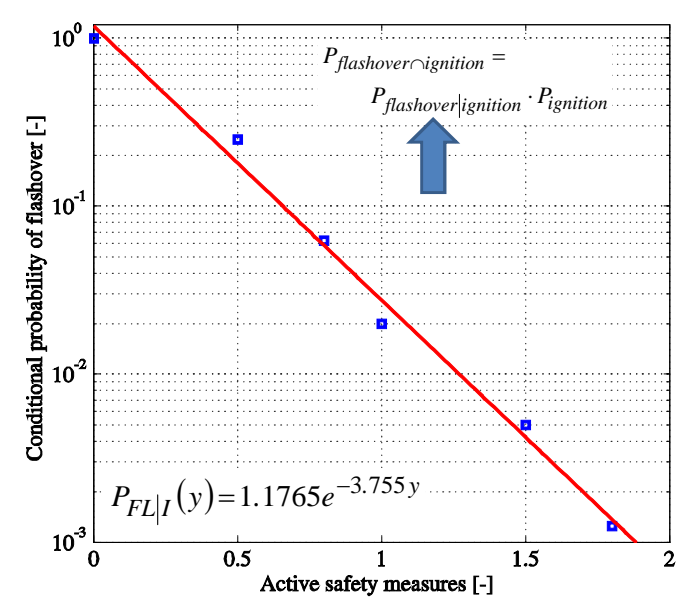

\begin{tabular}{c|c|c|c|c|c|c} 
Active safety measure & $\mathrm{a}$ & $\mathrm{b}$ & $\mathrm{c}$ & $\mathrm{d}$ & $\mathrm{b}+\mathrm{d}$ & $\mathrm{c}+\mathrm{d}$ \\
\hline $\begin{array}{c}\text { Cost }\left[€ / \mathrm{m}^{2}\right] \\
\text { Relative cost of safety } \\
\text { measure }\end{array}$ & 0 & 25 & 40 & 50 & 75 & 90 \\
\hline$P_{\text {flashover } \mid \text { ignition }}$ & 1 & 0.25 & 0.0625 & 0.02 & 0.005 & 0.00125
\end{tabular}

Scenario:

- a: None of active safety measure is applied

- b: Automatic fire detection and alarm by heat

- c:Automatic fire detection and alarm by smoke

- d: Sprinkler system

- b+d: Sprinkler system + detection by heat

- c+d: Sprinkler system + detection by smoke

Fig. 2 Cost and efficiency of different active safety measures including the installation, construction and maintenance for the service life.

As it can be seen in Fig. 2, different scenarios are considered within the investigation where alarm and water extinguish systems are applied separately and together. The presented conditional 
probabilities have been selected according to (Handbook 5, 2005). A continuous function has been fitted on he presented discrete probabilities. The supposed costs of active measures contain the estimated cost of installation, pipes, wires, servicing.

The conditional probabilities of structural failure have been calculated using reliability analyses (FORM), where the thicknesses of intumescent coating (Fig. 1b) were varied with one amplifier from zero to triple value (Fig. 3). The critical temperature of the elements was calculated within a time-step analysis, on the basis of their load bearing capacity on elevated temperature. The strength and stability resistances were evaluated according to (EN3-2, 2005). The details of the reliability analysis can be found in (Balogh and Vigh, 2015a).

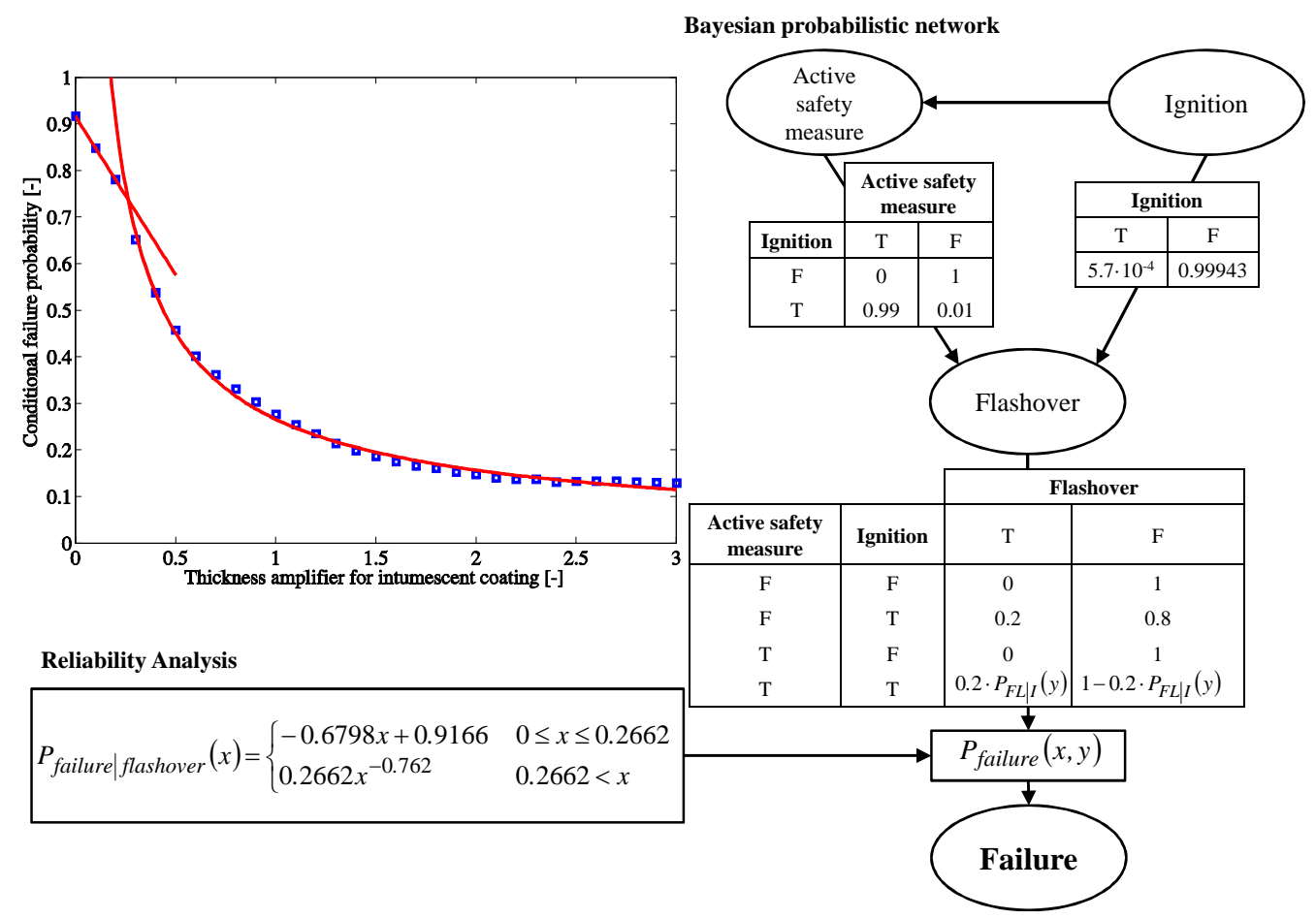

Fig. 3 Conditional probability of failure and Bayesian network.

A simple Bayesian network is implemented where the probability of flashover can be calculated as follows according to the Bayesian theorem (Faber, 2009):

$$
\begin{gathered}
P_{\text {flashover }}=P(F L=T \mid A=T, I=T) \cdot P(A=T, I=T)+P(F L=T \mid A=F, I=T) \cdot P(A=F, I=T)+\ldots \\
+P(F L=T \mid A=T, I=F) \cdot P(A=T, I=F)+P(F L=T \mid A=F, I=F) \cdot P(A=F, I=F)
\end{gathered}
$$

where $F L, A, I$ flashover, active safety measure and ignition respectively,

$T, F \quad$ true and false event.

As it can be seen in Fig. 3, a small chance of malfunction of active measures is considered in the network, while a further reduction is involved the calculation related to the fact that professional fire brigade may be available within at least 30 minutes from the site (Handbook 5, 2005).

\section{COST FUNCTION}

The optimum reliabilities are calculated through optimization where the minima of the cost function has to be found. The cost function is composed on the following way similarly to (Holickỳ., 2011). In $E q$. (3) $P_{\text {failure }}(x, y)$ refers to failure probability related to the service life which equals to 50 years.

$$
C_{\text {tot }}(x, y)=C_{f} \cdot P_{\text {failure }}(x, y)+C_{0}+C_{1} \cdot x+C_{2} \cdot y+0.01 C_{f} \cdot P_{\text {ignition }}+0.05 C_{f}
$$

where $C_{f}, C_{0}, C_{1}, C_{2}$ failure cost, initial cost, cost of passive and active safety measures, $x, y \quad$ amount of applied passive and active safety measures. 
In Eq. (3), the last two terms refer to the damage cost which is caused by moderate fire (quenched before flashover) and by safety measures (e.g. damage caused by sprinkler system and/or firefighting). $C_{f}, C_{1}$ and $C_{2}$ are varied through the study, however reference values are assumed to be as 3 million $€, 550 € /$ frame and $50 € / \mathrm{m}^{2}$, respectively. $C_{f}$ contains direct (e.g. value of stored material or the construction of a new storage hall) and indirect cost components (e.g. missing income or malfunction in production). $\mathrm{C}_{0}$, which remains unchanged, is set equal to $4600 € /$ frame (including the sheeting, purlins and bracing elements). The listed costs have been obtained with the consideration of Hungarian circumstances based on consultations with engineers.

\section{RESULTS}

The cost function of the investigated structure, which is obtained using the reference cost values for $C_{f}, C_{1}$ and $C_{2}$, can be seen in Fig. 4a. The minimum life cycle cost, which is marked with blue point, equals to cca. $37300 €$. In order to achieve this minimum cost, the designer of the facility has to use only passive protection with slightly thicker layers of intumescent coating than by prescriptive design since the resulted amplifier equals to 1.256. In the investigated case the ratio between the unit cost of passive and active safety measures is $C_{1} / C_{2}=0.0965$. The calculated optimal reliability index is $\sim 2.91$ which is lower than the suggested lowest target value in (EN0, 2002) for CC1 lower consequence class. In Fig. 4a a continuous red line shows which sets satisfy the criteria of EN 1990:2002. When target values of JCSS Probabilistic Model Code (JCSS, 2000) are considered as the reference, it can be seen that the calculated reliability index is between 2.55 and 3.21 values which are given for minor and moderate consequences, respectively.
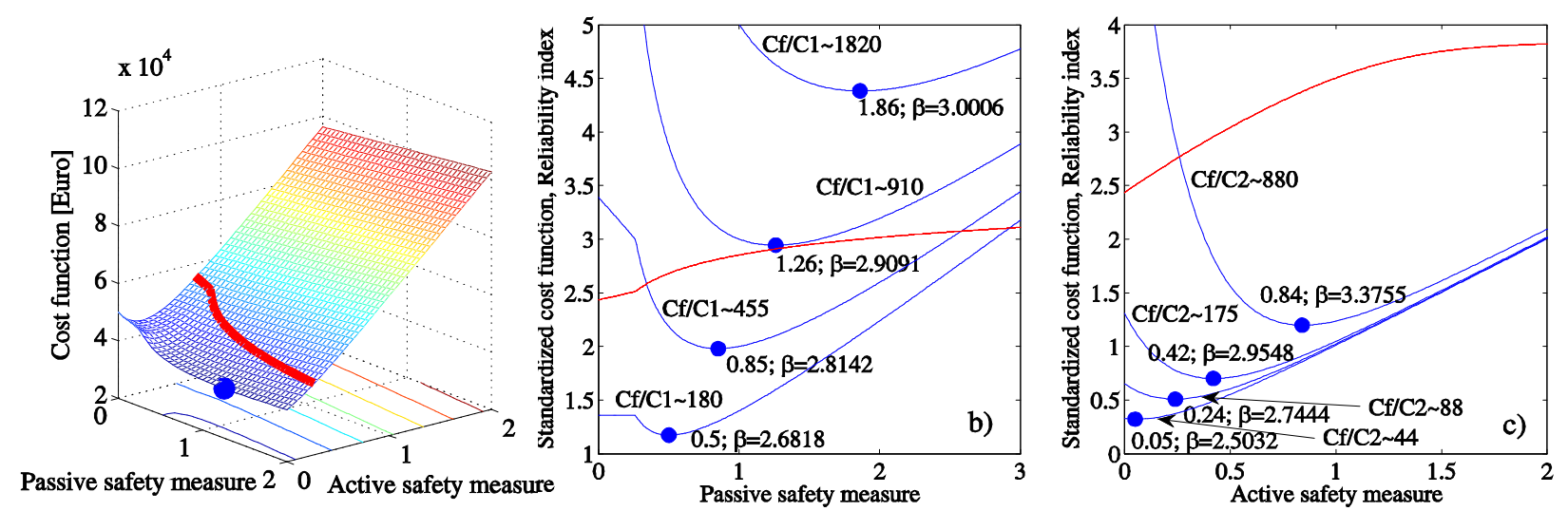

Fig. 4 a) Cost function with minimum cost; b)-c) Standardized cost functions and reliability indices for passive and active safety measures, respectively.

In Fig. 4b and 4c, the minimum life cycle costs and reliability indices can be seen for different cases. The aim of the investigation is to obtain what would be the optimum target value for reliability index if passive and active safety measures were used separately. In the figures the socalled standardized cost functions (Holickỳ, 2011) can be seen which are formulated as follows:

$$
\kappa_{t o t, C_{1}}(x, y)=\left(C_{t o t}(x, y)-C_{0}\right) / C_{1} ; \quad \kappa_{t o t, C_{2}}(x, y)=\left(C_{t o t}(x, y)-C_{0}\right) / C_{2}
$$

The $C_{1}$ and $C_{2}$ costs are varied from $50 \%$ to $500 \%$ and from $10 \%$ to $200 \%$ of the original value, respectively. If the $C_{f}$ failure cost were varied it would lead to the same results as it can be seen later. In case of the investigated storage hall, the optimal reliability varies from 2.6 to 3.0 for a reasonable range of the $C_{f} / C_{1}$ ratio. Due to the demanding design case and the fact that there is no linear connection between the thickness of intumescent coating and the steel temperature, the passive safety measure is not seemed enough effective to increase economically the structural reliability. If the aim was to satisfy a target value equal to $\beta=3.3$ (EN0) both type of safety measures would have to be applied.

The effectiveness of active safety measures is also investigated separately to the passive fire protection. Essentially it means that the structural reliability is ensured through reducing the probability of severe fire very low. It can be seen in Fig $4 \mathrm{c}$ that $\beta=3.3$ or higher reliability indices 
can be achieved only with deploying alarm and water extinguish system. Similarly to the passive protection, if the relative cost of safety measure is relatively high lower optimum value for reliability is observed.

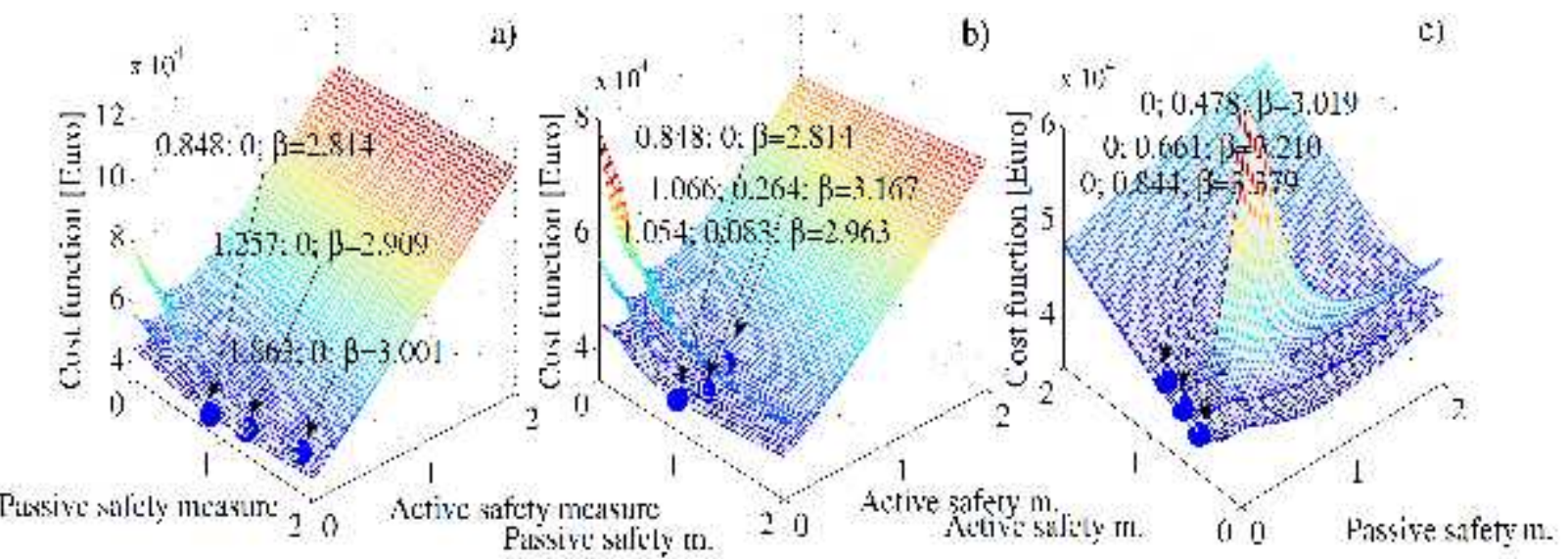

Fig. 5 Different cost functions: $C_{f}$ equals to 50,100, $200 \%$ of the reference value and $C_{2}$ equals to a) $100 \%$; b) $50 \%$; c) $20 \%$ of the reference cost.

In case of the investigated structure, the selected reference values for costs have resulted that only passive fire protection should be used in order to achieve minimum total cost. When the ratio between the cost components changes, the optimal solution may be related for such case where both type of safety measures are applied. Fig. 5 summarizes the results of an investigation in which $C_{f}$ and $C_{2}$ cost factors have been varied in order to show the optimum for different cases. The higher surfaces are related to higher $C_{f}$ value. If the ratio $C_{1} / C_{2}$ ratios is lower than $\sim 0.2$ the optimums are related cases where only passive measures are applied. When $C_{1} / C_{2}$ reaches $\sim 0.4-0.5$ or a higher value, the optimum can be achieved using only active measures. If $C_{1} / C_{2}$ is between 0.2 and 0.4 both safety measures are necessary for optimal reliability. It has to be noted that these statements are given for the case of optimal reliability and not for the case of certain target value from the code.

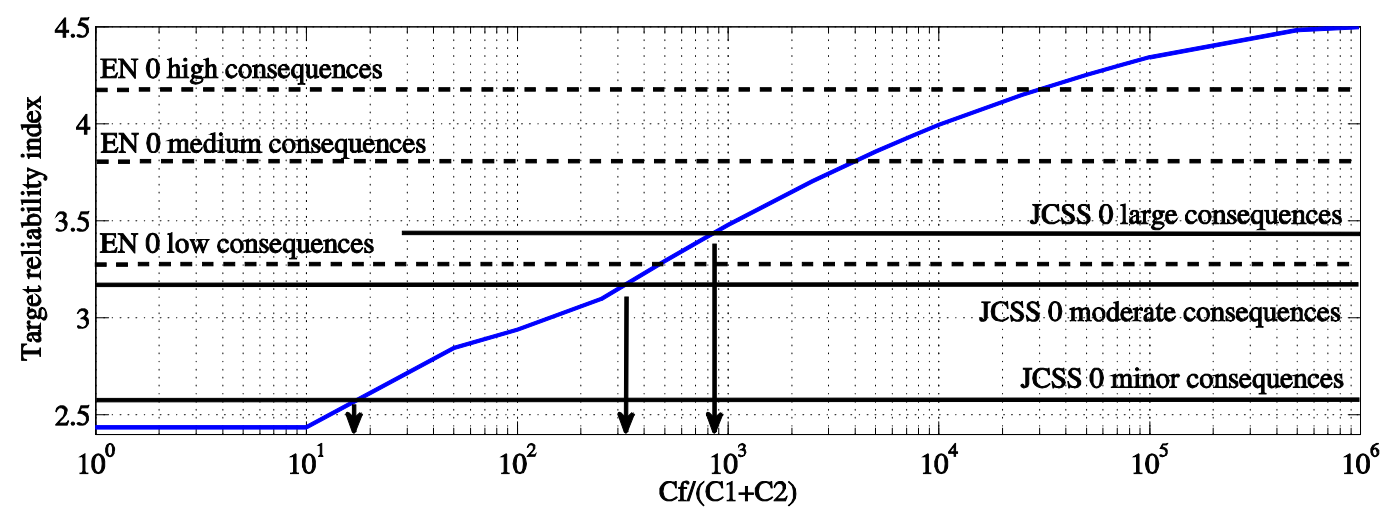

Fig. 6 Optimal reliability indices for various consequences

In a lot of design cases, it can be a problem to choose the target reliability index for the engineer. For example in EN0 the consequence classes are mainly differentiated by the function of the building, however even in case of a storage building the consequence class should be changed when the economic consequences are too high or low. It is investigated what would be the optimal target reliability for various consequence costs by investigated case. The results are summarized in Fig. 6 . The suggested values for reliability indices by codes are also shown in the figure. In case target values of JCSS Probabilistic Model Code, normal relative cost of safety measure is selected due to the moderate variability in the design problem.

The resulted curve can be divided into three main parts, where safety measures are not necessary $\left(C_{f} f\left(C_{1}+C_{2}\right) \unlhd 10\right)$, where only passive protection is needed $\left(10<C_{f}\left(C_{1}+C_{2}\right) \underline{-}\right.$-300) and where both 
types of safety measures should be applied $\left(300<C_{f}\left(C_{1}+C_{2}\right)\right)$. The reliability cannot be lower than $\sim 2.4$ because the occurrence of ignition is given as a discrete number in literature (Handbook 5, 2005) The consequence ratios for the JCSS reliability indices can be selected as 20, 300 and 900, respectively for minor, moderate and large consequence classes. In case of the investigated design problem the $C_{f} f\left(C_{1}+C_{2}\right)$ ratio equals to 80 , for this reason the target reliability should be selected for 3.21 according to JCSS or for 3.3 according to EN0. It would require $13 \%$ and $20 \%$ increase in the cost compared with the optimal reliability which equals to $\sim 2.9$.

\section{CONCLUSIONS}

In this paper, the calculation of the optimum reliability is presented for a tapered steel frame structure exposed to severe fire. The optimum reliability index of the investigated building is $\sim 2.9$ and based on the consequences it should be increased if the aim were to satisfy the criteria of EN0 and JCSS. The value of the cost function would be increased by 10-20\% if the recommended values of JCSS and EN0 ( $\beta=3.21$ and $\beta=3.3$, respectively) were satisfied. The target reliability indices of JCSS are seemed to be closer to the optimal solutions in fire design situation. EN0 does not give any suggestions for extreme loading conditions and the suggested values (obtained for permanent situations) are seemed too high. It has been shown that by lower consequences only passive protection is needed, however both types of safety measures should be applied by higher consequences. If the cost of active safety measures were lower it would be economic to ensure the reliability only with active measures in order to reduce the possibility of flashover very low. However, practically the usage of passive protection or the combination of safety measures results optimum reliability. It can be concluded that the appropriate range for target reliability would be from 2.5 to 3-3.5 for practically expectable cases. The presented results can help to the engineers by the selection of target reliability of steel framed industrial buildings.

\section{ACKNOWLEDGMENTS}

This paper was supported by the János Bolyai Research Scholarship of the Hungarian Academy of Sciences. The presented results are part of the "HighPerFrame" R\&D project Nr. GOP-1.1.1-112012-0568, supported by the Új Széchenyi Terv.

\section{REFERENCES}

Balogh T., Vigh L.G., 2015a. Optimal design of tapered steel portal frame structures subjected to fire effects (in Hungarian). MAGESZ Steel Structures, $1^{\text {st }}$ special issue, 84-94.

Balogh T., Vigh L.G., 2015b. Optimal design of tapered steel portal frame structures subjected to seismic effects (in Hungarian). MAGESZ Steel Structures, $1^{\text {st }}$ special issue, 95-106.

Cadorin J.F., Pintea D., Franssen J.M., 2001. The Design Fire Tool OZone V2.0 - Theoretical Description and Validation On Experimental Fire Tests, 1st draft, University of Liege, Belgium.

EN0: EN 1990:2002, Basis of structural design, European Standard, CEN, Brussels.

EN1-2: EN 1991-1-2:2002, Actions on structures - Part 1-2: General actions - Actions on structures exposed to fires, CEN, Brussels.

EN3-2: EN 1993-1-2:2005, Design of steel structures - Part 1-2: General rules - Structural fire design, CEN, Brussels.

EN 13381-8:2013. Test methods for determining the contribution to the fire resistance of structural members - Part 8: Applied reactive protection to steel members, CEN, Brussels

Faber M.H., 2009. Risk and Safety in Engineering (Online Lecture Notes), Zürich, Switzerland.

Holicky M., 2011. The target reliability and working life, in Safety and Security Engineering IV, Southempton, Boston, USA: WIT Press.

Holickỳ M., Schleich J. B., 2001. Modelling of a Structure under Permanent and Fire Design Situation, in Safety, Risk, Reliability - Trends in Engineering, 21-23 March 2001, Malta, p. 1001-1006.

Joint Committee on Structural Safety (JCSS), 2000. Probabilistic Model Code.

Leonardo da Vinci Pilot Project, 2005. Implementation of Eurocodes - Design of Buildings for the Fire Situation (Handbook 5), Luxemburg.

Dunamenti Ltd., 2015. Technical data sheet of Polylack A intumescent painting (in Hungarian), http://www.dunamenti.hu/ 